\title{
Effects of Metal Fillers on Properties of Epoxy for Rapid Tooling Inserts
}

\author{
Mohd Tanwyn Mohd Khushairi", Safian Sharif*, Khairur Rijal Jamaludin ${ }^{\$}$, Amrifan Saladin Mohruni ${ }^{\&}$ \\ ${ }^{\#}$ Education \& Training Office, German-Malaysian Institute, Kajang, 43000, Malaysia \\ Email:tanwyn@gmi.edu.my \\ *Faculty of Mechanical Engineering, Universiti Teknologi Malaysia, Johor Bahru, 81310, Malaysia, \\ Email:safian@utm.my \\ ${ }^{\$}$ UTM Razak School of Engineering \& Advanced Technology, Universiti Teknologi Malaysia, Kuala Lumpur, 54100, Malaysia \\ Email: khairur.kl@utm.my \\ ${ }^{\&}$ Faculty of Engineering, Sriwijaya University, Palembang, 30662, Indonesia \\ Email:mohrunias@unsri.ac.id
}

\begin{abstract}
Metal filled epoxy has been recognised as an alternative material used in rapid tooling application such as core and cavity for injection moulding. The addition of fillers into the metal filled epoxy has proven to increase the epoxy's mechanical performance such as wear, strength, improved machinability and thermal properties. Physical and thermal properties such as density, thermal diffusivity, thermal conductivity and compressive strength were analysed to evaluate the effects of inclusion of metal fillers such as copper and brass particles into the blended epoxy matrix. Brass and copper powders were added separately ranging from $10 \%, 20 \%$ and $30 \%$ of its weight into the aluminium filled epoxy mix ratio. Increased density, thermal diffusivity, and thermal conductivity values were evident with a linear trend when both filler compositions were increased from $10 \%$ to $30 \%$. Brass and copper density values of $2.22 \mathrm{~g} / \mathrm{cm}^{3}$ and $2.08 \mathrm{~g} / \mathrm{cm}^{3}$ respectively were recorded at the highest filler composition. Copper fillers with $30 \%$ composition in epoxy matrix exhibited the highest average value of thermal diffusivity of $1.12 \mathrm{~mm}^{2} / \mathrm{s}$ and thermal conductivity of $1.87 \mathrm{~W} / \mathrm{mK}$, while the inclusion of brass showed no significant improvement in the properties. Compressive strength increased from $76.8 \mathrm{MPa}$ to 93.2 MPa with $20 \%$ of brass fillers and $80.8 \mathrm{MPa}$ with $10 \%$ of copper fillers composition. The addition of more metal fillers resulted in a decrease in compressive strength due to the presence of porosity. This study validated previous researchers that fillers enhance mechanical, thermal properties and density of aluminium filled epoxy.
\end{abstract}

Keywords - epoxy; fillers; density; thermal diffusivity; thermal conductivity; compressive strength

\section{INTRODUCTION}

Tooling design such as plastic injection moulds and metal stamping dies involve extensive steps of manufacturing processes due to the stringent requirements of the end product, where dimensional accuracy and good surface finish are paramount. Mould and die components are usually fabricated from conventional, $\mathrm{CNC}$ machining, electro discharge machining (EDM) processes and finally going through an extensive manual polishing process which is expensive and time-consuming. CNC milling has limited capability when machining complicated surface geometry and may require fabrication of additional fixtures for holding the work piece [1].
Manufacturers should take advantage of the rapid prototyping (RP) and rapid tooling (RT) applications to produce parts for short run production as well as for cost optimisation, instead of building hard tooling. Pouzada outlined faster delivery periods, higher demand for quality, reduced product development phase and adapting to globalisation have made industries to sort for alternative production methods which include rapid tooling and using of alternative materials [2].

Application of RT is aimed to cut cost and reduce production time, hence several methods have been explored via direct and indirect tooling methods. Direct methods utilise RP to build inserts or moulds, while indirect techniques manipulate RP part as a master pattern to produce moulds or castings [3]. Filled epoxy is classified as a thermoset material which is suitable for tooling applications 
such as injection mould inserts and core as well as thermoforming patterns.

One of the main issues in the development RT for moulding process is the low thermal conductivity, resulting in slow heat transfer out from the mould inserts. Rapid heating and cooling can further degrade the mould inserts and cause part shrinkage, further affecting the part quality and dimensional accuracy [4]. Thermal distribution in an aluminium epoxy mould with conformal cooling channels in relation to the moulding time was investigated by Khurram et. al. during injection moulding process [5]. However, the part quality and its relationship with the thermal conductivity of the epoxy mould inserts were not addressed. Hence, there is limited literature on improving the thermal conductivity of rapid tooling, as it is an important aspect to be studied considering that the moulded part quality is dependent on the RT technique used.

As reported by Pouzada, RT materials including metal filled epoxy mould have an influence on the mechanical characteristics of the moulded part [2]. Adding metallic fillers such as aluminium or copper increases the thermal properties of the epoxy matrix while adding milled carbon or glass fibres improves mechanical properties such as wear resistance [6]. In addition, fillers tend to increase the density of the epoxy composition, thus further improves its machinability injection moulding application.

The purpose of this paper is to investigate the effect of different compositions of aluminium filled epoxy with the addition of metal fillers of copper and brass particles on the mechanical and thermal properties of the epoxy tooling. These properties include density, thermal properties and compressive strength of the epoxy tooling that will be used as mould inserts and cavities during injection moulding process. The findings of this study are expected to assist the related tooling industries as well as plastics industries in selecting suitable metal fillers with appropriate mixture ratio in the fabrication of mould inserts for the production of plastic parts using injection moulding process.

\section{MATERIAL AND METHOD}

\section{A. Sample Preparation}

Epoxy with aluminium filled (EA), RenCast CW 47 supplied by Huntsmann Advanced Materials is mixed with its hardener Ren HY 33 at a ratio of 100:15 as recommended by the supplier [7]. Aluminium particles with a concentration between $25 \%-30 \%$ are in the epoxy mixture, while brass and copper particles were added separately to the EA concentration, at three different levels of 10\%, 20\% and $30 \%$ of the mixture weight.

The mixtures were poured into rubber moulds which were prepared using vacuum casting process with specific specimen shapes for various properties assessments including compressive strength, hardness, wear test and thermal conductivity, before proceeding through a final degassing process. The procedures are clearly illustrated in Fig. 1. In order to achieve the appropriate mixture ratio and a hardness value of the metal epoxy, the optimum process was followed accordingly which are degassing time of 60 minutes, followed by pre-curing the samples at $50^{\circ} \mathrm{C}$ overnight and then continued with $180^{\circ} \mathrm{C}$ for 14 hours in the oven [8]. Temperature increase was set at $1{ }^{\circ} \mathrm{C} /$ minute and after curing, the hardened epoxy material was left to cool in the oven to ambient temperature.

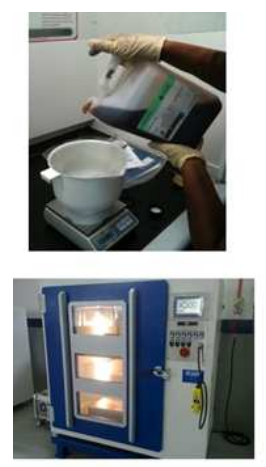

\section{Mixing \& \\ blending of \\ EA and fillers}
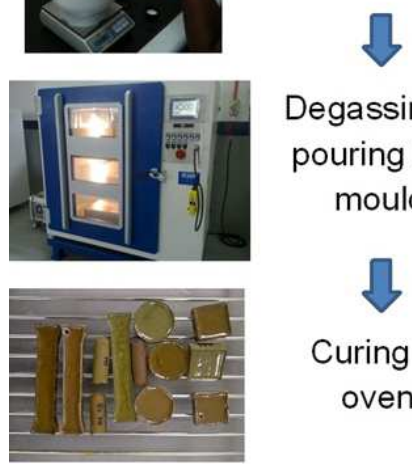

Degassing \&

pouring into

mould

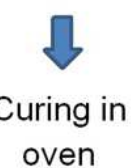

Fig. 1 Aluminium filled epoxy preparation with filled metals

\section{B. Density Test}

RenCast CW 47 filled epoxy resin has a density of 1.85 $\mathrm{g} / \mathrm{cm}^{3}$, as supplied by the manufacturer [7]. Densities of other commercially available materials are between 1.7 to $2.0 \mathrm{~g} / \mathrm{cm}^{3}$ [9]. Samples containing mixtures of brass and copper fillers in the epoxy matrix were cut into small sizes, weighed in air and water to determine their relative densities. This method corresponds to ASTM D-792-13, and the relative density, $D$ (at $20^{\circ} \mathrm{C}$ ) is determined using equation (1).

$$
D=\frac{a b}{a-b+c-d}
$$

\section{Thermal Diffusivity Test}

Cured epoxy samples were milled to $5 \mathrm{~mm}$ thickness, and 2 pieces of $\phi 30$ discs were prepared for thermal diffusivity test. Thermal conductivity analyser, model TPC 2500s with hot wire thermal constants analyser software version 5.9 was used for this purpose, equipped with Kapton® insulated sensor that operates between $-160^{\circ} \mathrm{C}$ to $300^{\circ} \mathrm{C}$ (Fig. 2). Samples were tested with output power set at $0.05 \mathrm{~W}$ and 200 points recorded within 10 seconds, based on ASTM C 1113 standard.

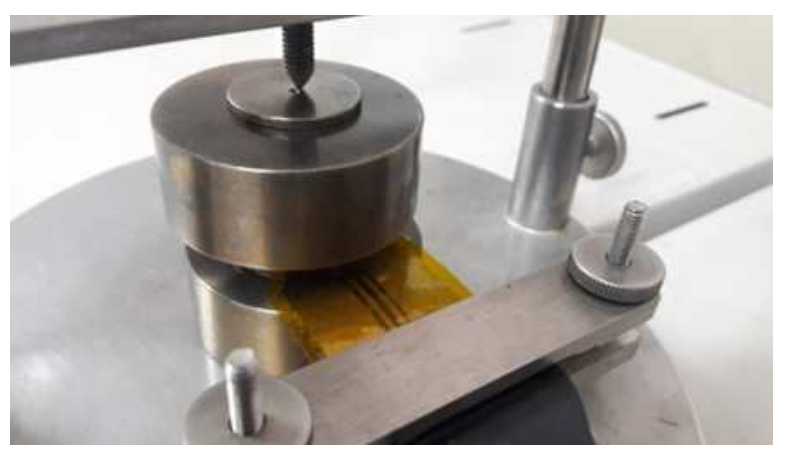

Fig. 2 Kapton ${ }^{\circledR}$ insulated sensor in between $\phi 30 \mathrm{~mm}$ disc samples 
Thermal diffusivity is described as how a material or solid can change its temperature [10]. It is represented by equation (2).

$$
\alpha=k / \rho c
$$

\section{Thermal Conductivity Test}

The test method is similar to thermal diffusivity test, by using the same samples sizes and equipment. The transfer of heat is conducted from high to low-temperature object. Heat transfer changes internal energy of objects when heat is applied and is governed by Fourier's law, according to the First Laws of Thermodynamics [11]. The equation is presented as follows.

$$
Q=-k A[d T / d X]
$$

Thermal conductivity is expressed in terms of the coefficient $k(\mathrm{~W} / \mathrm{m} . \mathrm{K})$. It is defined as the rate of transmission of heat energy from one molecule to another. Temperature gradient $[\mathrm{dT} / \mathrm{dX}]$ is denoted with a negative sign to indicate opposite direction of the heat flow. Equation 3 corresponds to a one-dimensional system in a steady state. However, heat in a body travels in three coordinate directions and is represented with a nonlinear or unsteady heat transfer system. Temperature gradient exists as a function of time when heat is conducted out from the body. It can be represented with lumped heat capacity system, with the assumption that a uniform temperature distribution exists throughout the body [11]. Lumped heat capacity can be analytically determined by equation (4).

$$
m c d T / d t+h A\left[T-T_{\infty}\right]
$$

\section{E. Compressive Strength Test}

ASTM D 695 standard was employed considering that the epoxy material is a rigid thermoset class of material [12]. A support jig was fabricated to hold the specimen upright, together with the top and bottom platens for the compressive test, as indicated in Fig. 3. Mild steel platens were fabricated with a surface diameter of $100 \mathrm{~mm} \times 10 \mathrm{~mm}$ thick, with the primary function to support the jig, and positioned between the upper crosshead and lower platen (Fig. 4).

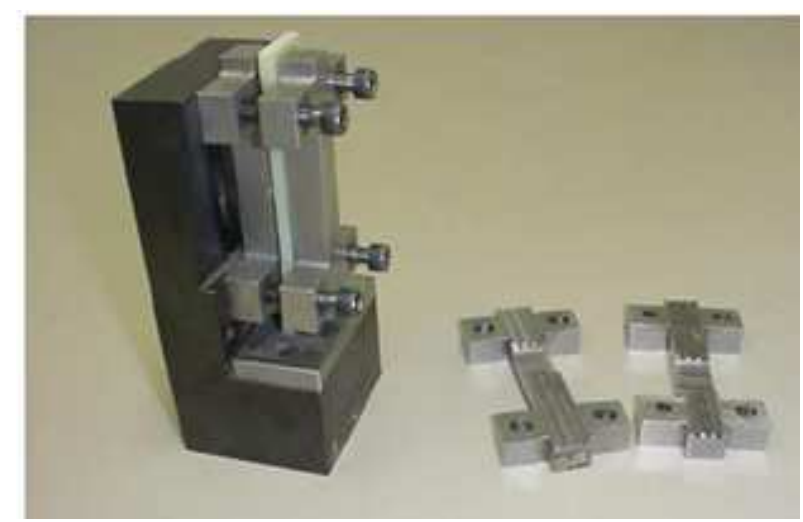

Fig. 3 Support jig for ASTM D 695 [13]

Instron 3300 series Universal Testing Machine with a maximum force of $50 \mathrm{kN}$ was used for the testing purpose. Compressive strength specimens were prepared with length $79.4 \mathrm{~mm} \times$ width $19 \mathrm{~mm}$, while the neck area was $12.7 \mathrm{~mm}$ wide and $5 \mathrm{~mm}$ thickness. Specimens consisting of different filler percentages were clamped between the jigs and subjected to a load at $10 \mathrm{~mm} / \mathrm{min}$. Data collected were compiled in the equipment software, Bluehill version 2.0 in the form of displacement $(\mathrm{mm})$ and load $(\mathrm{kN})$.

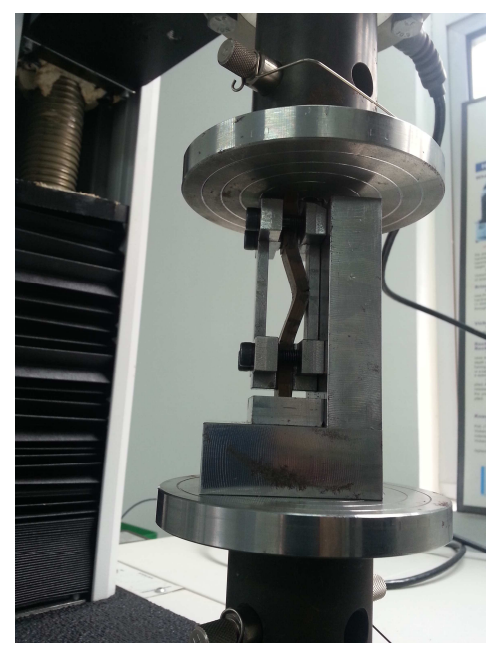

Fig. 4 Position of jig in between compression platens

\section{RESULT AND DISCUSSION}

\section{A. Density Test Results}

Previous studies with metallic and non-metallic fillers indicated that density increases with the addition of fillers percentage. Bhagyashekar et. al. conducted a study using epoxy resins (LY556 resin of M/S Ciba Geigy) with silicone carbide, graphite, copper and aluminium fillers, and the results showed linear trends with an increase of filler composition [14]. Similar trends were recorded when gypsum, alumina and silicon nitride mixed with epoxy and measured in Shore D hardness [15].

Based on the density analysis conducted, both brass and copper fillers increased the density of cured mixture of EA as indicated in Table 1. However, the actual density of RenCast CW 47 filled epoxy is $1.70 \mathrm{~g} / \mathrm{cm}^{3}$ as obtained from the test result which differs slightly with the manufacturer value of $1.85 \mathrm{~g} / \mathrm{cm}^{3}$.

TABLE I

AVERAGE DENSITY of EA WITH DifFERENT METAL FILLERS

\begin{tabular}{|l|c|c|c|}
\cline { 2 - 4 } \multicolumn{1}{c|}{} & \multicolumn{3}{c|}{ Density $\left(\mathrm{g} / \mathrm{cm}^{\mathbf{3}}\right)$} \\
\hline Fillers & $\mathbf{1 0 \%}$ & $\mathbf{2 0 \%}$ & $\mathbf{3 0 \%}$ \\
\hline Brass & 1.85 & 2.01 & 2.22 \\
\hline Copper & 1.83 & 1.96 & 2.08 \\
\hline
\end{tabular}

The improved density values for both filler compositions are due to the increase in the average percentage areas of copper and brass fillers in the EA matrix, and the linear trend is indicated in Fig. 5. 


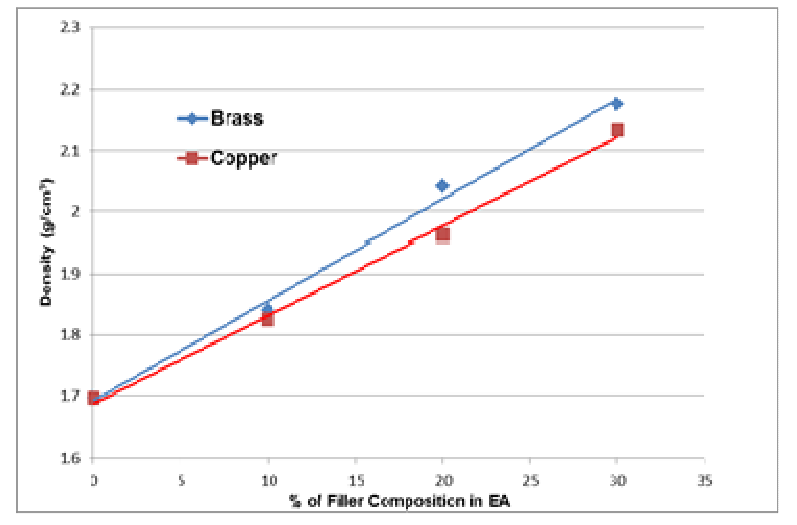

Fig. 5 Effects of fillers on EA density

Area of fillers was determined with phase analysis method using Huvitz HRM-300 high power microscope, equipped with $10 x$ digital magnification camera. Images were processed with digital microscopy analyser software (IMT ISolution DT). Aluminium has an average area of $26.7 \%$ from the mixture, while brass and copper fillers values are indicated in Table 2. Average areas for both fillers increased with higher composition from $10 \%$ to $30 \%$ that directly increased the mass of EA composition.

TABLE II

MEAN SizE AND AvERAGE AREA OF FILLER IN EA

\begin{tabular}{|l|c|c|c|}
\hline \multicolumn{4}{|c|}{ Composition of fillers in EA } \\
\hline Brass & $\mathbf{1 0 \%}$ & $\mathbf{2 0 \%}$ & $\mathbf{3 0 \%}$ \\
\hline Mean size (mm) & 1.62 & 2.10 & 2.22 \\
\hline Ave. Area (\%) & 4.36 & 5.50 & 6.76 \\
\hline Copper & $\mathbf{1 0 \%}$ & $\mathbf{2 0 \%}$ & $\mathbf{3 0 \%}$ \\
\hline Mean size (mm) & 1.22 & 1.48 & 1.68 \\
\hline Ave. Area (\%) & 1.44 & 3.00 & 3.78 \\
\hline
\end{tabular}

\section{B. Thermal Diffusivity Results}

From the thermal test conducted, the average thermal diffusivity of EA was recorded as $0.70 \mathrm{~mm}^{2} / \mathrm{s}$. Table 3 shows the average thermal diffusivity values for brass and copper fillers between $10 \%$ to $30 \%$ in EA composition. No significant effect was observed when brass fillers were added to the mixture, only reduced values at $10 \%$ and $20 \%$ composition. The value improved with $30 \%$ brass filler, indicating a small increase of $0.04 \mathrm{~mm}^{2} / \mathrm{s}$, as compared to the original value.

TABLE III

AVERAGE THERMAL DIFFUSIVITY OF EA WITH FILLERS

\begin{tabular}{|l|c|c|c|}
\cline { 2 - 4 } \multicolumn{1}{c|}{} & \multicolumn{3}{c|}{ Thermal Diffusivity $\left(\mathbf{m m}^{\mathbf{2}} / \mathbf{s}\right)$} \\
\hline Fillers & $\mathbf{1 0 \%}$ & $\mathbf{2 0 \%}$ & $\mathbf{3 0 \%}$ \\
\hline Brass & 0.644 & 0.657 & 0.740 \\
\hline Copper & 0.837 & 0.923 & 1.112 \\
\hline
\end{tabular}

Copper fillers provided better thermal diffusivity values as compared to brass as indicated in Fig. 6. Further, it correlates with the increase of percentage area from $1.44 \%$ to $3.78 \%$ based on results in Table 2 . Improved thermal diffusivity will directly increase thermal conductivity based on equation (2), which enables better heat dissipation from the mould cavity and core. This effect cools the mould plastic parts faster and reduces internal stresses, thus further improves the mechanical strength of injected plastic part.

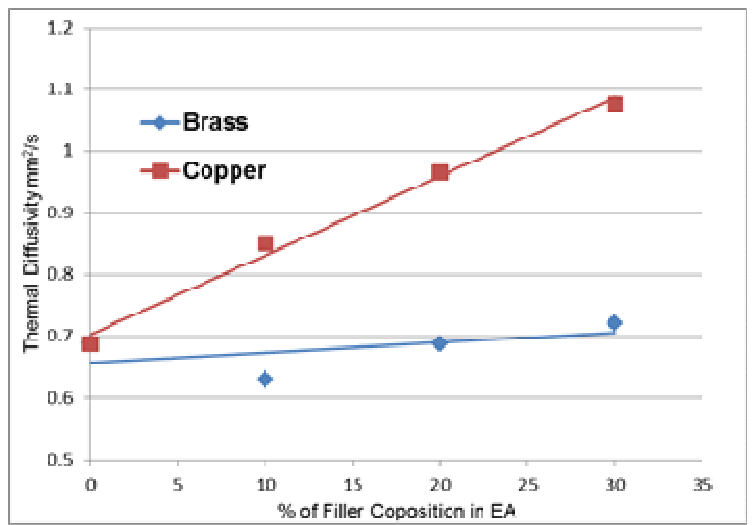

Fig. 6 Effects of fillers on EA thermal diffusivity

\section{Thermal Conductivity Results}

Data generated from the thermal analyser software indicated an average value of $1.35 \mathrm{~W} / \mathrm{m} . \mathrm{K}$ for EA. Thermal conductivity, $k$ values for unfilled epoxy ranges from $0.6-$ $0.8 \mathrm{~W} / \mathrm{m} . \mathrm{K}$, while commercially available EA is 1.43 $\mathrm{W} / \mathrm{m} . \mathrm{K}$ [9]. Based on the results in Table 4, the values of $10 \%$ and $20 \%$ brass composition were less than the EA average value. As observed, there is no significant effect on the EA mixture when adding brass fillers, only a slight increase of $0.02 \mathrm{~W} / \mathrm{m} . \mathrm{K}$ was recorded from the average value. The thermal conductivity of copper filled EA mixture improved at different compositions, indicating a linear increase as shown in Fig. 7. This is due to the fact that copper has higher $k$ value than brass, at $231 \mathrm{~W} / \mathrm{m} . \mathrm{K}$, as compared to the brass at $70 \mathrm{~W} / \mathrm{m} . \mathrm{K}$ in solid form [16]. This finding is similar to a study, whereby silicon carbide ( $\mathrm{SiC}$ ) improved the thermal conductivity from 0.45 to $1.3 \mathrm{~W} / \mathrm{m} . \mathrm{K}$ from $0 \%$ to maximum of $40 \% \mathrm{SiC}$ powder, added into the epoxy mixture [17].

TABLE IV

AVERAGE THERMAl CONDUCTIVITY OF EA WITH FILLERS

\begin{tabular}{|l|c|c|c|}
\cline { 2 - 4 } \multicolumn{1}{c|}{} & \multicolumn{3}{c|}{ Thermal Conductivity (W/m.K) } \\
\hline Fillers & $\mathbf{1 0 \%}$ & $\mathbf{2 0 \%}$ & $\mathbf{3 0 \%}$ \\
\hline Brass & 1.18 & 1.21 & 1.37 \\
\hline Copper & 1.66 & 1.73 & 1.87 \\
\hline
\end{tabular}

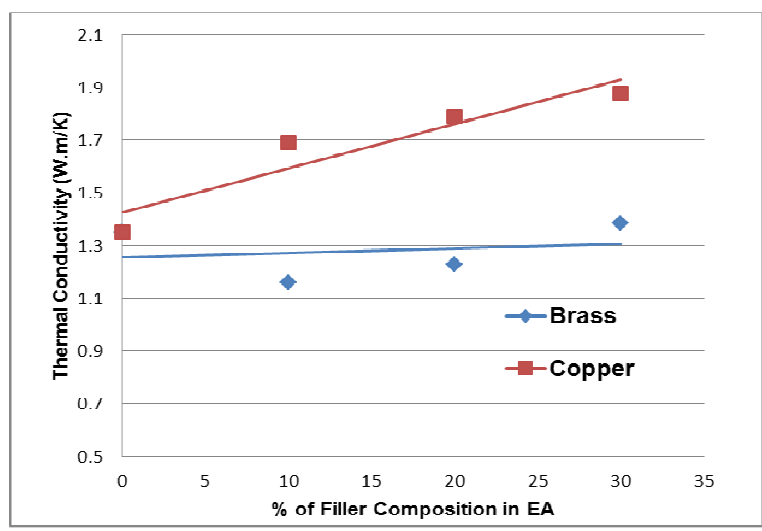

Fig. 7 Effects of fillers on EA thermal conductivity 


\section{Compressive Strength Results}

Data collected from Bluehill 2 software were presented in the stress-strain diagram, where strain is calculated from the displacement during the test. The stress - displacement diagram is displayed in Fig. 8. Samples exhibited deflection during force loading and cracked at the centre area when reaching the maximum load (Fig. 9).

As shown in Table 5, adding brass fillers increases the average compressive strength of EA mixture which is 76.8 $\mathrm{MPa}$, obtained from the test results. Brass filers at $20 \%$ composition demonstrated the highest average value of 93.23 $\mathrm{MPa}$, however, recorded a reduction in strength at $30 \%$ composition. Fig. 10 indicates a nonlinear trend for brass fillers upon reaching $30 \%$ composition. It was reported by $\mathrm{Ma}$ et. al. that adding more fillers beyond $20 \%$ to $25 \%$ composition in the epoxy matrix reduces the compressive strength, hence supporting this finding [15].

TABLE V

COMPRESSIVE STRENGTH VALUES OF EA WITH FILLERS

\begin{tabular}{|l|c|c|c|}
\cline { 2 - 4 } \multicolumn{1}{c|}{} & \multicolumn{3}{c|}{ Compressive Strength (MPa) } \\
\hline Fillers & $\mathbf{1 0 \%}$ & $\mathbf{2 0 \%}$ & $\mathbf{3 0 \%}$ \\
\hline Brass & 95.61 & 93.23 & 92.69 \\
\hline Copper & 80.83 & 81.51 & 73.17 \\
\hline
\end{tabular}

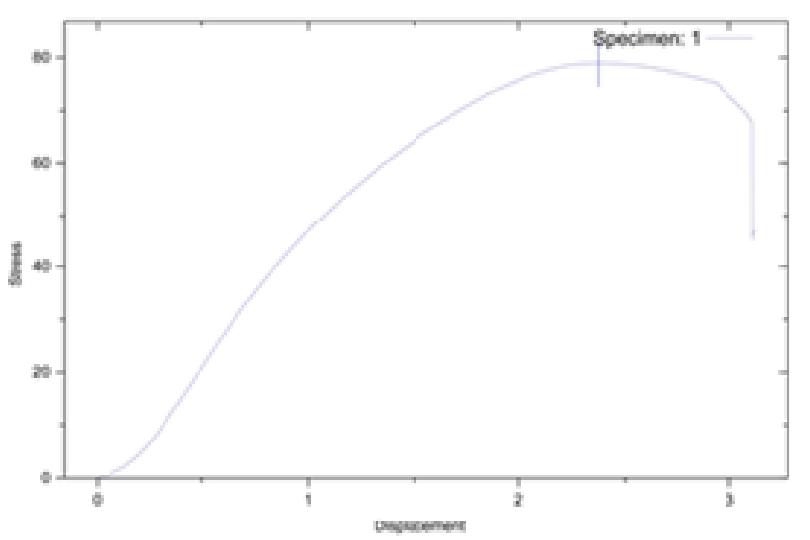

Fig. 8 Compressive stress (MPa) vs. displacement (mm)

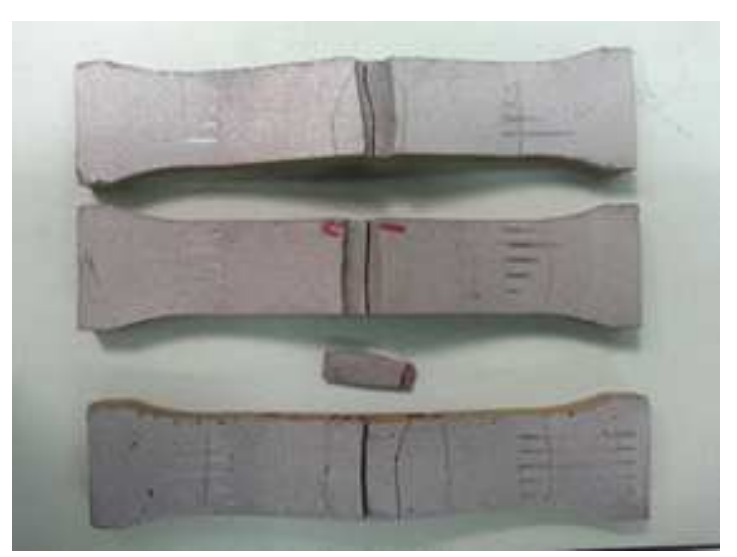

Fig. 9 Visible cracks after compression tests

EA mixture with copper fillers showed a downward trend of its compressive strength after $10 \%$ composition (Fig. 10). This is contrary to the findings by Bhagyashekar et. al., whereby higher copper filler percentages improved the compressive strength of the specimens, as fillers aided the resistance of the material under compression load [18]. The reason is due to the different test specimens used in other studies which are in the form of the prism $(12.7 \times 12.7 \mathrm{x}$ $25.4 \mathrm{~mm}$ ) or cylindrical shape of $\phi 12.7 \times 25.5 \mathrm{~mm}$. In this study, the samples were prepared as dumbbell specimens, with a thickness of $5 \mathrm{~mm}$ or less. This is to simulate ribs and bosses in mould cavities that are exposed to high injection and holding pressures during the flow and solidification of molten material. Compressive stresses were created and applied to thinly walled profiles, ribs, and bosses. Hence they can easily deflect or fracture during the injection phase.

Figs. 11a, b, and c show the dispersion of copper fillers in the samples, where trapped air is observed as black patches. White particles are aluminium with an average size of $5.7 \mu \mathrm{m}$ to $10.7 \mu \mathrm{m}$. Trapped air or voids formed porosity that existed in copper-EA mixture. More copper fillers resulted in higher porosity because trapped air takes a longer time to be released although the dispersion of both fillers was uniform throughout the matrix. There were fewer voids found in the brass mixture samples. This was evident in the composition analysis with ASTM E 1245 method. Table 6 indicates the mean percentage area of the void distribution, identified as trapped air in EA mixture with individual fillers.

From the data obtained, it was observed that maximum diameter of voids increased from $10 \%$ to $30 \%$ for copper fillers. Voids are represented by equal circle diameter as the trapped air that formed a round shape. Results in Table 7 shows that void diameters in EA with brass filler composition are consistent in size, as compared to EA with copper fillers.

TABLE VI

VoID AREA By PERCENTAGE IN EA COMPOSITION

\begin{tabular}{|l|c|c|c|}
\cline { 2 - 4 } \multicolumn{1}{c|}{} & \multicolumn{3}{c|}{ Mean \% Area of voids } \\
\hline Fillers & $\mathbf{1 0 \%}$ & $\mathbf{2 0 \%}$ & $\mathbf{3 0 \%}$ \\
\hline Brass & 0.8 & 0.8 & 1.2 \\
\hline Copper & 2.1 & 3.7 & 5.9 \\
\hline
\end{tabular}

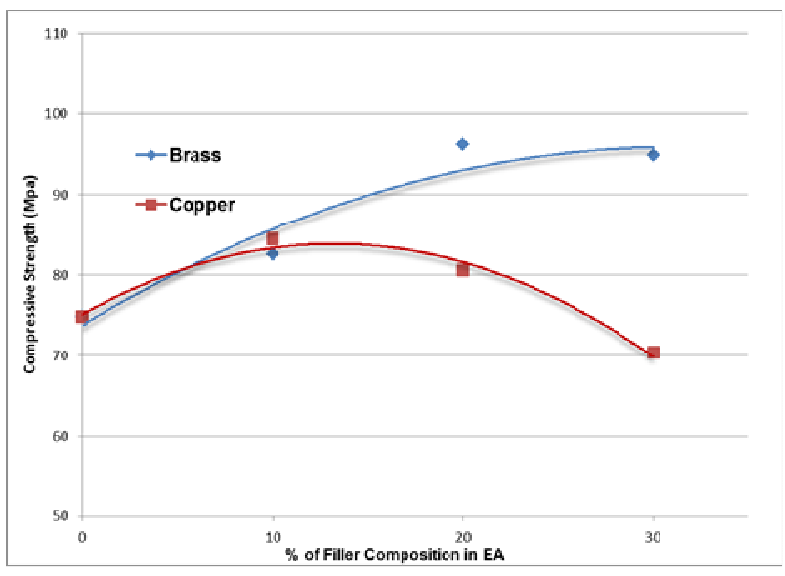

Fig. 10 Effect of filler composition on compressive strength in EA 


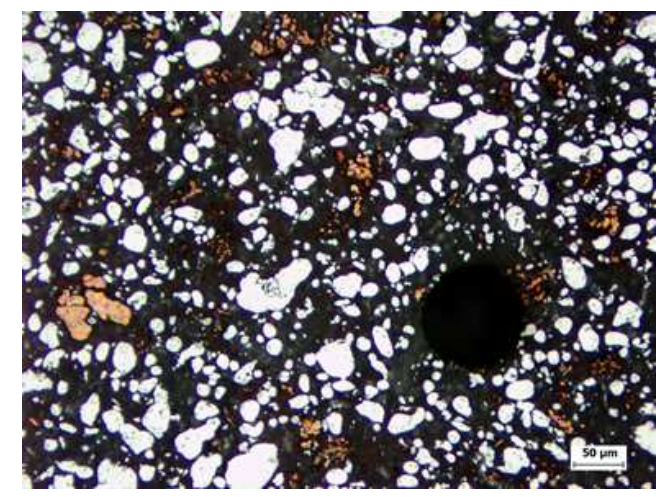

Fig. 11a Void in EA with $10 \%$ copper fillers

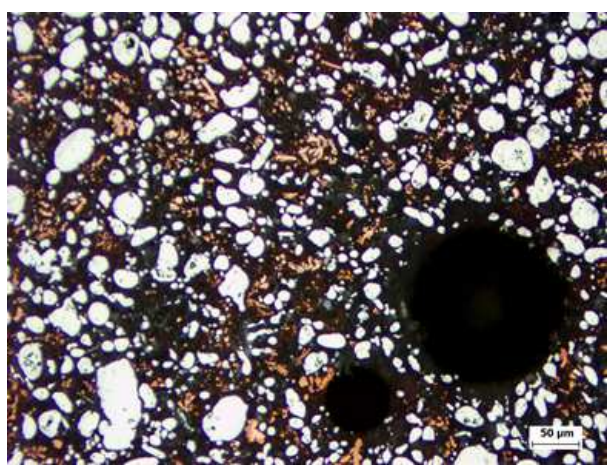

Fig. 11b Void in EA with $20 \%$ copper fillers

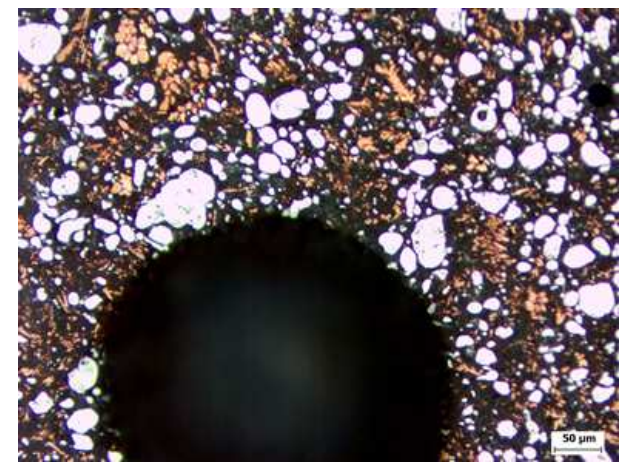

Fig. 11c Void in EA with $30 \%$ copper fillers

TABLE VII

MAXIMUM SIZE OF VOIDS IN EA COMPOSITION

\begin{tabular}{|l|c|c|c|}
\cline { 2 - 4 } \multicolumn{1}{c|}{} & \multicolumn{3}{c|}{ Maximum size of voids $(\boldsymbol{\mu m})$} \\
\hline Fillers & $\mathbf{1 0 \%}$ & $\mathbf{2 0 \%}$ & $\mathbf{3 0 \%}$ \\
\hline Brass & 43.1 & 40.2 & 41.8 \\
\hline Copper & 66.8 & 134.9 & 171.1 \\
\hline
\end{tabular}

\section{CONCLUSION}

In this study, the following conclusions were drawn: The brass and copper concentration in aluminium filled epoxy (EA) significantly improved the density of the mixture, exhibiting a linear increase with higher filler weight. Brass recorded the highest density of $2.22 \mathrm{~g} / \mathrm{cm}^{3}$ at $30 \%$ of its composition weight. This is expected to improve the mould insert performance in terms of durability and machinability. Thermal diffusivity was observed to increase with higher copper concentration up to $1.112 \mathrm{~mm}^{2} / \mathrm{s}$, which is $59 \%$ gain from the value of EA without fillers. Adding brass did not significantly improve its thermal properties. However, at $30 \%$ of brass fillers, the value increased to $0.74 \mathrm{~mm}^{2} / \mathrm{s}$ as compared to EA at $0.7 \mathrm{~mm}^{2} / \mathrm{s}$. Highest thermal conductivity is obtained with $30 \%$ copper filled EA at $1.85 \mathrm{~W} / \mathrm{m} . \mathrm{K}$, which is $39 \%$ increase from EA's value. Similar to the effect in thermal diffusivity, brass fillers have no effect on the mixture's thermal conductivity even up to $30 \%$ composition. The rate of heat dissipation is an important factor in order to cool the mould inserts rapidly and enable stress relief of the moulded parts during solidification. Brass exhibited higher compressive strength compared to coppers fillers in EA. However, filler contents beyond $20 \%$ composition reduce the compressive strength. This effect is similar with copper fillers since voids were found in the samples resulting in more apparent breakage. The void areas increased with the increase of copper filler ratio in EA mixture. Adding metal fillers in epoxy material improved the compressive strength, hardness and wore resistance hence increase the mould insert's performance and life [19]. A right balance of thermal and mechanical properties is sought after. Hence copper and brass fillers are suitable at $10 \%$ and $30 \%$ composition respectively. Further study on the moulding process is necessary to evaluate the moulded part's mechanical properties with different inserts.

\section{NOMENCLATURE}

a mass of specimen and wire in air

$b$ mass of wire in air g

c mass of wire with end immersed in water $\mathrm{g}$

$d$ mass of wire and specimen immersed $\mathrm{g}$ in water

$k \quad$ thermal Conductivity

$c \quad$ specific heat of material

$Q \quad$ heat transfer rate

$A$ area

$d T$ temperature differential

$d X \quad$ thickness

$\mathrm{W} / \mathrm{m} . \mathrm{K}$ $\mathrm{J} / \mathrm{kg} . \mathrm{K}$

W

$\mathrm{m}^{2}$

${ }^{\circ} \mathrm{C}$ or $\mathrm{K}$

$\mathrm{m}$

$\mathrm{kg}$

mass flux $=\rho V$

volume

temperature

$T_{\infty} \quad$ ambient temperature

$d t \quad$ time differential

$h \quad$ heat transfer coefficient

${ }^{\circ} \mathrm{C}$

${ }^{\circ} \mathrm{C}$

$\mathrm{S}$

$\mathrm{W} / \mathrm{m}^{2 \circ} \mathrm{C}$

Greek letters

$\alpha \quad$ thermal diffusivity $\mathrm{mm}^{2} / \mathrm{s}$

$\rho$ density of material $\mathrm{kg} / \mathrm{m}^{3}$

\section{ACKNOWLEDGMENT}

The authors wish to thank German-Malaysian Institute, Universiti Teknologi Malaysia and Sriwijaya University for the cooperation and assistance throughout conducting this research. Special appreciation to the Research Management Centre of UTM and Ministry of Higher Education Malaysia for the financial support through the Fundamental Research Grant Scheme R.K130000.7840.4F819. 


\section{REFERENCES}

[1] M. Minhat, S.B. Mohamed, M.S. Kasim, M.A. Sulaiman and Z.I. Rizman, "Advanced manufacturing of an aircraft component (fishhead): a technology review on the fabrication," Int. J. Adv. Sci. Eng. Info. Technol., vol. 6 no. 5, pp. $734-739,2016$.

[2] A.S. Pouzada, "Hybrid moulds: a case integration of alternative materials and rapid prototype for tooling," Vir..and Phys. Proto., vol. 4, no. 4, pp. 195 - 202, 2009.

[3] P. Dunne, S.P. Soe, G. Byrne, A. Venus and A.R. Wheatley, "Some demands on rapid prototypes used as master patterns in rapid tooling for injection moulding," J. Mater. Process. Technol., vol. 150, pp. $201-207,2004$.

[4] J.I. Segal, and R.I. Campbell, "A review of research into the effects of rapid tooling on part properties," Rapid Prototyping J., vol. 7, no. 2, pp. $90-98,2001$.

[5] Khurram. A, Ahmad M.A.R, and Vijay. R.R, "Prototype production and experimental analysis for circular and profiled conformal cooling channels in aluminium filled epoxy injection mould tools," Rapid Prototyping J., vol. 19, no. 4, pp. 220 - 229, 2013.

[6] P.V. Vasconcelos, F.J. Lino, A. Magalhães, Baptisa and R.J.L. Neto, "Impact fracture study of epoxy-based composites with aluminium particles and milled fibres," J. Mater. Process. Technol., vol. 170, pp. $277-283,2005$.

[7] "RenCast CW47 datasheet 2007," Huntsman Adv. Materials GmbH, Switzerland.

[8] M.T.M. Khushairi, S. Sharif, and J.S.M. Ani, "Parameter design of hardness for metal filled epoxy matrix," Adv. Mat. Res., vol. 1125, pp. 152-156, 2015.

[9] "Handling procedure mould production with MCP tooling resins EP 310 (ver. 3)," MCP-HEK Tooling GmbH, Germany.
[10] N.S. Gokhale, S.S. Deshpance and S.V. Bedekar, A.N. Thite, Practical Finite Element Analysis $-1^{\text {st }}$ Edition, Finite to Infinite, Pune, India, 2008.

[11] J.P Holman, Heat Transfer, New York: McGraw Hill, 2001

[12] T.L. Richardson and E. Lokensgard, Industrial Plastics, Theory and Applications, New York: Delmar Publishers Inc., 1996.

[13] A.R. Wolfe and M.Weiner, "Compression testing - comparison of various test methods," Composites convention and trade show, 2004, American Composites Manufacturers Assoc., Tampa, USA.

[14] M.S. Bhagyashekar, K. Rao and M.V.G.K. Rao, "Studies on rheological and physical properties of metallic and non-metallic particulate filled epoxy composites," J. Reinf. Plast. Compos., vol. 28, pp. $2869-2878,2009$.

[15] S. Ma, I. Gibson, G. Balaji, and Q.J. Hu, "Development of epoxy matrix composites for rapid tooling applications," J. of Mat. Proc. Tech, vol. 192-193, pp. 75-82, 2007.

[16] S. Suresh, M.A. Jamil, S. Sulaiman and M.R.M. Shokor, "Optimization of electrode material for EDM die-sinking of Titanium Alloy grade 5 - Ti6A14V," Int. J. Adv. Sci. Eng. Info. Technol., vol. 6 no. 4, pp. 534 - 539, 2016.

[17] T. Tomori, S. Melkote and M. Konis, "Injection mould performance of machined ceramic filled epoxy tooling boards," J. Mater. Process. Technol., vol. 145, pp. 126-133, 2004

[18] M.S. Bhagyashekar, and M.V.G.K. Rao, "Characterization of mechanical behaviour of metallic and non-metallic particulate filled epoxy matrix composites," J. Reinf. Plast. Compos., vol. 29, pp. 30 42, 2010.

[19] M.T.M. Khushairi, S. Sharif, and J.S.M. Ani, "Evaluation of mechanical properties of filled epoxy composite for improving mould performance - a review," Adv. Mat. Res., vol. 735, pp. 13 18,2015 . 